\title{
In search of professional consensus in defining and reducing low-value care
}

\section{"What constitutes \\ low-value care lies in \\ the eye of the beholder"}

Ian A Scott FRACP, MHA, MEd ${ }^{\text {.2 }}$

Stephen J Duckett DSC, FASSA, FAHMS

1 Princess Alexandra Hospital, Brisbane, QLD.

2 University of Queensland, Brisbane, QLD.

3 Grattan Institute, Melbourne, VIC.

ian.scott@ health.qld.gov.au
T he costs and harms associated with systemic overdiagnosis and overtreatment are receiving international attention. Clinicians and their professional organisations are obliged to assume resource stewardship as an ethical responsibility as embodied in the 2002 millennium professional charter.

Low-value care is use of an intervention where evidence suggests it confers no or very little benefit on patients, or risk of harm exceeds likely benefit, or, more broadly, the added costs of the intervention do not provide proportional added benefits. The lattermost concept involves considering benefit and cost relative to those of alternative care options, as embodied in cost-effectiveness analysis. ${ }^{1}$ Examples of high-value and low-value care occupy a matrix which emphasises this relativity of benefit over cost (Appendix 1). Care may be high (or low) value if, despite higher (or lower) costs, it confers proportionately greater (or lower) benefit. Choosing low-value care consumes resources that could have been expended on alternative forms of care conferring greater levels of benefit, either to the patient in question or to other patients.

Efforts to reduce low-value care run counter to the dominant financial incentives in our fee-for-service (private sector) and activity-based funding (public sector) systems that reward volume over value, challenge the cultural assumption that more is better, and raise concerns about stinting on necessary care. Historically, most research and effort in quality improvement has focused on underuse of high-value care ${ }^{2}$ - a legitimate concern - rather than overuse of low-value care.

\section{How much low-value care exists?}

It has been claimed that at least $20 \%$ of health care expenditure in the United States is wasted on activities that add no value. ${ }^{3}$ Studies using US Medicare claims data suggest that almost half of beneficiaries receive some form of low-value care. ${ }^{4}$ While comparable statistics for Australian health care are not available, reviews of Medicare Benefits Schedule (MBS) items have suggested that at least 150 commonly used tests and procedures are associated with little high-quality evidence of benefit, and that for some there is evidence of harm for their assigned indications. ${ }^{5}$ To date, fewer than $5 \%$ of MBS items have been closely scrutinised for their evidence-based worth. Operations such as arthroscopic debridement for uncomplicated knee osteoarthritis are frequently performed despite randomised trials showing no benefit. ${ }^{6}$ Investigation requests - such as those for vitamin $B_{12}$, folate ${ }^{7}$ and vitamin $D^{8}$ assays, and for computed tomography scans for back pain and chest diseases ${ }^{9}$ - have surged in

\section{Summary}

- Care that confers no benefit or benefit that is disproportionately low compared with its cost is of low value and potentially wastes limited resources.

- It has been claimed that low-value care consumes at least $20 \%$ of health care resources in the United States - the comparable figure in Australia is unknown but there is emerging evidence of overuse of diagnostic tests and therapeutic procedures.

- Very few clinical interventions are of no value in every clinical circumstance, and efforts to label interventions as being so will meet with professional resistance.

- In the context of complex and highly individualised clinical decisions, nuanced clinical judgements of experienced and well informed clinicians are likely to outperform any service-level measurement and incentive program aimed at recognising and reducing low-value care.

- Public policy interventions should focus on supporting clinician-led efforts to seek professional consensus on what constitutes low-value care and the best means for reducing it.

recent years despite considerable doubt as to their usefulness to patient care. Screening and diagnostic tests and procedures predominate over therapeutic agents in most studies of overuse. ${ }^{4}$ Some are of high value in high-risk populations (such as screening colonoscopy in patients younger than 60 years of age with premalignant colon conditions or family history of bowel cancer) but assume much lower value when extended to low-risk populations (patients older than 75 years of age with no risk factors). ${ }^{5}$ Overuse may also partly explain the marked geographical variation in ageand sex-standardised rates of cardiac catheterisation (7.4-fold variation) and hysterectomies (4.0-fold variation)..$^{10}$ In 2006, the Productivity Commission estimated that the efficiency of Australian health care could be improved by up to $20 \%$ by aligning performance with best practice across a range of service areas. ${ }^{11}$

The science of measuring overuse is in its infancy - a recent review noted that only 37 fully specified measures exist for overuse, compared with hundreds for underuse..$^{12}$ Measures may take several forms (see Box) but all are constrained by the lack of systematic collection of granular clinical data at the level of individual patient care that captures the indications for the intervention (why was it given?) and the views and preferences of patients (in cases of marginal benefit, was there a strong patient preference to receive it?). Such nuanced data are necessary in deciding when the same service is high value in one patient but low value in another. Electronic health records which mandate insertion of 


\section{Measurements of low-value care}

\section{Direct measures}

- Proportion of patients with specific condition (eg, low back pain) who received a specific intervention (eg, imaging of the lumbosacral spine) in the absence of extenuating circumstances (eg, history of cancer)

- Legitimate indications for intervention are tightly specified

- Concordant with a "do not do" recommendation

\section{Indirect measures}

- Rates of use of specific interventions in specific patient populations in whom it is accepted that such interventions should be used selectively (eg, coronary angiography in patients with chest pain suggestive of myocardial ischaemia)

- Assumes rates that are consistently higher than average reflect some degree of inappropriate use in the presence of discretionary indications

- Concordant with a "do not do routinely" recommendation

- Useful when legitimate indications for intervention and appropriate rates of use are uncertain

\section{Rates of negative results of diagnostic tests}

- Rates at which results of diagnostic tests are determined to be negative (eg, no significant narrowing of coronary arteries found on coronary angiography)

- Adds to indirect crude rates of use

- High rates of negative results suggest weak or no legitimate indication in most patients

\section{Marked variations in rates of use}

- Rates of use of interventions which show marked variation between homogenous populations of patients, providers and health services (eg, 10-20-fold variation in rates of coronary artery revascularisation in patients with coronary artery disease between geographically similar populations serviced by same peer group providers)

- Unwarranted variation suggests overuse by at least some providers in population studies in which legitimate variation in rates due to differences in patient characteristics, provider expertise and service capacity has been minimised by comparing clinically similar patient populations, equivalent provider groups and peer hospitals

indications, linked to utilisation databases (pathology, radiology, MBS, Pharmaceutical Benefits Scheme), may enable development of data repositories that are capable of interrogation at the individual level using unique identifiers. Although routine data can suggest that a low-value treatment has been provided, they cannot reveal why it occurred.

Attention must also be given to potential unintended adverse consequences of overuse measurement such as underuse of indicated care, biased patient selection, harm to doctor-patient relationships, and shifts to alternative tests and treatments in clinical settings not subject to measurement. ${ }^{13}$

\section{What strategies can be deployed to reduce low-value care?}

Currently, there is considerable government interest in Australia in using policy levers to minimise overservicing and contain health care costs. Strategies focus on decision making involving consumers (demand side) or providers (supply side). It should be noted at the outset that the impact of these strategies appear unaffected by whatever system of health care financing (fee-for-service, capitation, or managed care) predominates in particular clinical settings. ${ }^{14}$
Demand-side levers targeting patients principally include financial incentives and education. Increasing patient cost-sharing by way of copayments for services is a blunt instrument and can lead to reduced use of both low-value and high-value care, as most patients cannot differentiate between the two. Indeed, patients overestimate benefit or underestimate harm in about two-thirds of clinical decisions amenable to benefit-risk analysis. ${ }^{15}$ Furthermore, most research on consumer education campaigns, including public reporting on provider performance, suggest that such campaigns are weak instruments for changing patient behaviour. ${ }^{16}$ Patient information and decision-aid approaches in the context of shared decision making show promise, ${ }_{1}^{17}$ but are currently confined to relatively few clinical scenarios.

Supply-side levers, aimed at health care providers, depend heavily on financial incentives which may be service specific (eg, pay-for-performance and prior authorisation) or population based (eg, risk-sharing, in which providers accept financial responsibility for total costs of care under bundled or blended care payment schemes). However, evidence of effectiveness of such incentives remains limited, ${ }^{18}$ and Australian trials of prepaid coordinated care (a blended payment scheme) for managing patients with diabetes have not been finalised. Removing or lowering Medicare rebates or diagnosis-related group payments for lowvalue interventions is another option. However, past efforts to substantially revise the MBS have failed and very few items have been removed from the schedule in the past decade. However, a major review process is currently underway. One innovative option is indication-specific pricing whereby remuneration for an intervention depends on the amount of benefit it confers for a specific indication, with the base price anchored to the indication for which it provides the most value, or linked to a preset value. ${ }^{19}$

As for information-based supply-side interventions, clinical practice guidelines, clinical audits and feedback, academic detailing, decision support and other professional educational interventions exert limited impact in curtailing inappropriate care. Embedding of decision support, quality measurement and instant feedback into electronic health records and handheld-device applications may help to reduce low-value care at the point of care. Examples include lung cancer guidelines in the US ${ }^{20}$ and various guidelines from Cancer Council Australia.

While waiting for digital solutions, analysing claimsbased data and identifying providers (as groups or as individuals) with inordinately higher rates of use compared with peer averages may be useful in terms of stimulating practice reviews for evidence of overuse. While such datasets are inexpensive, widely available, and population-based, they lack detailed clinical information. Population-based outcome monitoring linked to professional incentives is another option; this approach is finding favour in the US in 
accountable care contracts which encourage decreased use of low-value care through partial capitation or shared savings.

\section{What is the role of clinicians in recognising} and minimising low-value care?

What constitutes low-value care lies in the eye of the beholder. Most clinicians regard very few interventions as conferring no benefit in all clinical circumstances. They are reticent in labelling a practice low value if, in their personal experience at least, the practice has stood the test of time and conferred benefit on some patients with no safety concerns.

Altering such perceptions is not easy. First, evidence of treatments that are of little or no benefit is viewed sceptically if it: is perceived as lacking objectivity, consistency or clinical plausibility; is not equally applicable to all individuals (different magnitude of effects or different patient valuations of benefit among different patient groups); or challenges strongly held professional beliefs based on personal experience and peer opinion. Information about what constitutes ineffective treatment is diffuse, sometimes low quality and hard to use.

Second, various cognitive factors distort perceptions of low-value care, ${ }^{21}$ reflecting clinician desire to avoid potential injustice to individuals, and their own sense of regret or medicolegal liability, from withholding interventions that may possibly bestow some benefit. In many such cases, the absence of any other viable treatment option pushes the clinician to offer the only available, but still low-value, treatment.

Third, external factors such as quality-of-care metrics, competitiveness in the medical marketplace, and organisational aspirations to be "centres of excellence" all encourage "thoroughness", pro-intervention bias and desire to meet expectations of patients, referring clinicians and corporate stakeholders at the risk of overservicing.

However, professional organisations in the US have begun the task of defining instances where the use of a particular intervention is likely to constitute lowvalue care. The American Board of Internal Medicine Foundation's Choosing Wisely campaign involves more than 60 specialty societies, each identifying at least five commonly encountered scenarios in their specialty where specific interventions should be avoided. ${ }^{22}$ Examples of how these can be applied in clinical practice are described in Appendix 2.

Critics worry that US specialty groups have found it easier to recommend reduction in use of services by other specialties compared with those within their own specialty, or focus solely on low-cost diagnostic tests, rather than address high-cost interventions specific to their own craft group. ${ }^{23}$ Nevertheless, it represents a beginning and the Royal Australasian College of Physicians ${ }^{24}$ and the National Prescribing Service (http://www. choosingwisely.org.au) are mounting similar campaigns. The US Preventive Services Task Force, the National Quality Forum and the American College of Physicians' High Value Care platform all seek to educate front-line clinicians on methods for identifying unnecessary and wasteful services. ${ }^{1}$

In the United Kingdom, the Academy of Medical Royal Colleges has released a report outlining the rationale and principles behind reducing low-value care, illustrated by numerous case studies. ${ }^{25}$ Specialty societies and researchers are employing expert panels equipped with the best available research syntheses to rank the level of appropriateness of different interventions using consensus methods and Delphi rounds. ${ }^{26}$ These activities recognise that most interventions are neither low value nor high value in all cases, and seek instead to identify their nuanced low-value and high-value applications according to clinical context.

Should clinicians be allowed to be the final arbiters of low-value care? In making complex and highly individualised clinical decisions, nuanced clinical judgements of experienced, well informed clinicians will arguably outperform any service-level measurement and incentive program aimed at recognising and reducing low-value care. Attempts to distil and apply evidence-informed "do not do" rules at the population level are bedevilled by the rule of legitimate exceptions when care is directed at specific individuals.

Moreover, in a recent national US survey, $92 \%$ of physicians said they felt responsible for ensuring patients avoid unnecessary tests and procedures, and 58\% believed that physicians were best positioned to do so. ${ }^{27}$ Arguably, deciding how and when to use limited health care resources are clinical questions that are best addressed by those with sufficient training and experience. Clinicians are more likely to respond to evaluations of quality by their peers than to adverse comments from non-clinical reviewers or managers, or to threats of financial sanctions and penalties for seemingly low-value care based solely on macro level analysis.

At the micro level, some physicians are establishing programs in their areas of practice that identify and remove low-value care using evidence of effectiveness, cost awareness, and regular audits and feedback. ${ }^{28}$ Training and education programs can enhance and assess the ability of aspiring clinicians to recognise and practice high-value care. ${ }^{29,30}$ Such bottom-up approaches are a good place to start and public policy interventions should support clinician-led efforts to seek professional consensus on what constitutes low-value care and the best means for reducing it.

Competing interests: No relevant disclosures.

Provenance: Not commissioned; externally peer reviewed.

(c) 2015 AMPCo Pty Ltd. Produced with Elsevier B.V. All rights reserved.

References are available online at www.mja.com.au. 
1 Owens DK, Qaseem A, Chou R, Shekelle P; Clinical Guidelines Committee of the American College of Physicians. High-value, cost-conscious health care: concepts for clinicians to evaluate the benefits, harms, and costs of medical interventions. Ann Intern Med 2011; 154: 174-180.

2 Runciman WB, Hunt TD, Hannaford NA, et al. CareTrack: assessing the appropriateness of health care delivery in Australia. Med J Aust 2012; 197: 100-105. https://www.mja.com.au/journal/2012/197/2/caretrackassessing-appropriateness-health-care-delivery-australia

3 Institute of Medicine. Best care at lower cost: the path to continuously learning health care in America. Washington, DC: National Academies Press, 2012. http://www.iom.edu/Reports/2012/Best-Care-at-LowerCost-The-Path-to-Continuously-Learning-Health-Care-in-America.aspx (accessed Jun 2015).

4 Schwartz AL, Landon BE, Elshaug AG, et al. Measuring low-value care in Medicare. JAMA Intern Med 2014; 174: 1067-1076.

5 Elshaug AG, Watt AM, Mundy L, Willis CD. Over 150 potentially low-value health care practices: an Australian study. Med J Aust 2012; 197: 556-560. https://www.mja.com.au/journal/2012/197/10/over-150-potentially-lowvalue-health-care-practices-australian-study

6 Bohensky MA, Sundararajan V, Andrianopoulos N, et al. Trends in elective knee arthroscopies in a population-based cohort, 20002009. Med J Aust 2012; 197: 399-403. https://www.mja.com.au/ journal/2012/197/7/trends-elective-knee-arthroscopies-populationbased-cohort-2000-2009

7 Willis CD, Metz MP, Hiller JE, Elshaug AG. Vitamin Bl2 and folate tests: the ongoing need to determine appropriate use and public funding. Med $J$ Aust 2013; 198: 586-588. https://www.mja.com.au/journal/2013/198/11/ vitamin-bl2-and-folate-tests-ongoing-need-determine-appropriate-useand-public

8 Bilinski KL, Boyages SC. The rising cost of vitamin D testing in Australia: time to establish guidelines for testing. Med J Aust 2012; 197: 90. https:// www.mja.com.au/journal/2012/197/2/rising-cost-vitamin-d-testingaustralia-time-establish-guidelines-testing

9 Mendelson RM, Murray CPJ. Towards the appropriate use of diagnostic imaging. Med J Aust 2007; 187: 5-6. https://www.mja.com.au/ journal/2007/187/1/towards-appropriate-use-diagnostic-imaging

10 Australian Commission on Safety and Quality in Health Care. Medical practice variation: background paper. Sydney: ACSQHC, 2013. http://www. safetyandquality.gov.au/wp-content/uploads/2013/10/SAQ110_Medical Practice_variation_V10_WEB.pdf (accessed Jun 2015).

11 Productivity Commission. Potential benefits of the National Reform Agenda. Report to the Council of Australian Governments, Canberra. Melbourne: PC, 2006. http://www.pc.gov.au/research/completed/ national-reform-agenda/nationalreformagenda.pdf (accessed Jun 2015)

12 Chan KS, Chang E, Nassery N, et al. The state of overuse measurement: a critical review. Med Care Res Rev 2013; 70: 473-496.

13 Mathias JS, Baker DW. Developing quality measures to address overuse. JAMA 2013; 309: 1897-1898.

14 Keyhani S, Falk R, Howell EA, et al. Overuse and systems of care: a systematic review. Med Care 2013; 51: 503-508.

15 Hoffmann TC, Del Mar C. Patients' expectations of the benefits and harms of treatments, screening, and tests: a systematic review. JAMA Intern Med 2015; 175: 274-286.

16 Hussey PS, Luft HS, McNamara P. Public reporting of provider performance at a crossroads in the United States: summary of current barriers and recommendations on how to move forward. Med Care Res Rev 2014; 71(5 Suppl): 5S-16S.

17 Stacey D, Bennett CL, Barry MJ, et al. Decision aids for people facing health treatment or screening decisions. Cochrane Database Syst Rev 2011; (10): CD001431.

18 Scott A, Sivey P, Ait Ouakrim D, et al. The effect of financial incentives on the quality of health care provided by primary care physicians. Cochrane Database Syst Rev 2011; (9): CD008451.

19 Bach PB. Indication-specific pricing for cancer drugs. JAMA 2014; 312: 1629 1630.

20 Neubauer MA, Hoverman JR, Kolodziej M, et al. Cost effectiveness of evidence-based treatment guidelines for the treatment of non-small-cell lung cancer in the community setting. J Oncol Pract 2010; 6: 12-18.

21 Hajjaj FM, Salek MS, Basra MKA, Finlay AY. Non-clinical influences on clinical decision-making: a major challenge to evidence-based practice. JR Soc Med 2010; 103: 178-187.

22 Cassel CK, Guest JA. Choosing wisely: helping physicians and patients make smart decisions about their care. JAMA 2012; 307: 1801-1802.

23 Morden NE, Colla CH, Sequist TD, Rosenthal MB. Choosing wisely - the politics and economics of labeling low-value services. N Engl J Med 2014; 370: 589-592.

24 Royal Australasian College of Physicians. EVOLVE: evaluating effectiveness. enhancing efficiencies. https://members.racp.edu.au/index cfm?objectid=3B8173E6-F3B9-C2FD-24B7E7353586BDEA (accessed May 2015).

25 Academy of Medical Royal Colleges. Protecting resources, promoting value: a doctor's guide to cutting waste in clinical care. November, 2014. http:// www.aomrc.org.uk/dmdocuments/Promoting\%20value\%20FINAL.pdf (accessed Nov 2014)

26 Basger BJ, Chen TF, Moles RJ. Validation of prescribing appropriateness criteria for older Australians using the RAND/UCLA appropriateness method. BMJ Open 2012; 2: e001431.

27 ABIM Foundation. Unnecessary tests and procedures in the health care system: what physicians say about the problem, the causes, and the solutions. Results from a national survey of physicians. May 1, 2014. http://www.choosingwisely.org/wp-content/ uploads/2014/04/042814_Final-Choosing-Wisely-Survey-Report.pdf (accessed Oct 2014).

28 Moriates C, Mourad M, Novelero M, Wachter RM. Development of a hospital-based program focused on improving healthcare value. J Hosp Med 2014: 9: 671-677.

29 McMillan JA, Ziegelstein RC. Implementing a graduate medical education campaign to reduce or eliminate potentially wasteful tests or procedures. JAMA Intern Med 2014; 174: 1693.

30 Ryskina KL, Korenstein D, Weissman A, et al. Development of a high-value care subscore on the internal medicine in-training examination. Ann Intern Med 2014; 161: 733-739. 